laborers or messenger boys," or any one else, except the best! physician whose services I can get.

My only variation from this rule is in cases of child birth, where, by the way, I generally use chloroform, believing it to be safer in this class of cases than any other.

I take a napkin large enough to fill a common tumbler about half full, when well packed in. I drop chloroform on this napkin in about drachm quantities at a time, and the irregularities of the patient's face render it impossible for my lady assistants to shut out entirely atmospheric air, should she hold the glass down close over the patient's nose and mouth. If I am using forceps I only use traction on my instrument for a minute or a two at a time, and in the intervals I scrutinize carefully the action of my anesthetic upon my patient. If I am performing version, that is a procedure which is soon ended and 1 can anesthetize my patient before I begin, and insensibility will continue long enough to finish the operation.

I quite agree with Dr. Galloway on the great importance of having a proper man as an anesthetizer, and believe with him further, that many of the untoward events that follow the major surgical operations are the result of an improperly administered anesthetic.

The only place where I have seen anesthetics given by men who did nothing else is in the hospitals of London, and they generally begin the anesthesia with nitro-oxid gas, and follow it immediately with ether. My experience, however, which is considerable, has led me to believe that men who are so chary of human life as to go to the expense and trouble of employing no one but a professional anesthetizer never employ a man who gives chloroform. There may be exceptions to this rule but if they exist I have never seen them.

Besides I quite agree with the Doctor that he has been treated in a most penurious manner by those to whom he has administered an anesthetic, and if he would only adopt an anesthetic that is, if figures and statistics are worth anything, from five to twenty-five times as safe as the one he uses, he, if skilled in its use, would be able to give a new record to some of the great operators who are now so fond of giving us their statistics, for I believe, Dr. Galloway, your position is of ten one of greater responsibility and more onerous than that of the man who wields the scalpel.

W. S. Caldwell, M.D.

\section{The Rubber Nipple on the Infant's Bottle.}

Beloit, Wis., Jan. 30, 1897.

To the Editor:--In your Editorial in today's Joursal on "Sanitary Trivialities" as a commendation of Dr. Ernest Wende of Buffalo for securing an ordinance prohibiting the use of rubber tubes on nursing bottles. At the last meeting of the Wisconsin State Medical Society I called attention to this crime (as it really is a crime), as follows: "The first thing a new father does when he finds the mother has no milk, is to go to the drug store for a nursing bottle. For some unknown reason the druggist is nearly always sure to give him one of these abominations, with a tube six inches long and a brush with which to wipe it out. I have often wished the druggists and manufacturers could take their food for life through such tubes. Somebody spoke about sterilizing bottles; but you can not sterilize these tubes, and the tubes are nearly always sold. If proper, I would like to make a motion that this society condemn most emphatically all these tubes, and that nothing but a pure nipple be used."

Dr. C. F. Dougherty of Muscoda, Wis., then said: "I am an advocate of common sense ounce bottle and nipple, but no rubber tube, because I think the milk can be more contaminated with germs through the long rubber tube than where they are not used, and I second the motion."

Several members spoke against this form of nursing bottle, but the discussion was ruled as out of order and the motion was laid on the table, though Dr. Dougherty earnestly protested and said that " to lay this motion on the table would result in laying many babies on the table in a coffin."

For the past three years I have carefully watched my cases of cholera infantum and acute milk infections, etc., and every case has occurred in bottle-fed children, and in children using these long tubes.

In our later days of asepsis and cleanliness it seems criminal to permit the sale of long hose nursing bottles, for it literally causes a "slaughter of the innocents." All honor to Dr. Wende for his course! Yours truly,

Ernest C. Hedm, M.D.

\section{'Testimonials.}

Nashville, Tenn., Dec. 18, 1896.

To the Editor:-As an editor you must be a very wise man, and as a wise man you must be possessed of all knowledge, therefore I write to you for information. I have just finished reading a neatly gotten up little pamphlet, a reprint from an article that lately appeared in one of the New York journals, sent me by the firm whose widely advertised tissue-former it advocates, and written by a "professor of anatomy and histology," with the title "F.S.S.C., London, etc.," and he hails from a place that would almost touch a line drawn between Chicago and here. "In Bright's disease," he says, "the administration of will of ten temporarily increase the number of casts in the urine, but it must be remembered that Bright's disease is not in itself the disease, but the result of albuminous deposits in the kidney resulting in ulcerations. A moderate use of -.__, however, has in most instances even controlled the ulceration."

Do you think, Mr. Editor, that he came over hese from England because they would not allow him to stay in that country any longer, or is this the latest pathology from London, with Dr. "F.S.S.C." right up to date and I away behind? Yours very truly,

ERnest B. SangreE, M.D.

\section{About Diploma Mills.}

Benton Harbor, Mich., Jan. 22, 1897.

To the Editor:-I understand the charter of the Illinois Health University has been annulled, but you will see that the same J. Armstrong, Mary E. Sellers, Demuheller \& Co. are in another "mill" of the same sort, and have supplied their graduates here with diplomas from the "Independent Medical College," which is run on exactly the same rules as their other "mill."

It seems that your State officers will allow this same company of confidence men to carry on their nefarious business regardless of anything or anybody; in fact it appears as though they were aids and abettors in their transactions. What can be done about it? Very respectfully, W. Ryno, M.D.

\section{Reviewers.}

Minneapolis, Jan. 22, 1897.

To the Editor:-Permit me to thank you for your editorial on "The Reviewing of Medical Publications" in the Jan. 16, 1897 , number of the Journal. It is not long ago that I put upon the market a text-book (Outlines of Materia Medica and Pharmacology). It had its weak points and no one would recognize these facts sooner than the author. One reviewer dwelt upon a typographic error in the spelling of one word, that was, however, properly spelled in many places throughout the book. In this same review the book was severely criticised because of its weakness in therapeutics when the preface distinctly stated that it was not a work on therapeutics.

Another reviewer who signed himself "R. W. W." and who is the American editor of an English work on materia medica, made the most vicious criticisms. At the same time they dis- 
played ignorance and injustice on their part. The book was open to criticism but not the kind of criticism it got. Very truly,

H. M. Bracken, M.D.

\section{Advertising.}

To the Editor:-It has for some time appeared to me that a few otherwise reputable physicians in the community in which I reside, have been guilty of flagrant wrongs in the way of allowing their names to be placed about in an advertising manner. The matter of which I have complained has been mentioned to some members of the profession and a few of them take the position that I am not correct. An expression on these points from the Journal of THE A MERICAN MEDiCaL Association would be appreciated. The matters to which I wish to direct your attention are, the placing of physicians' names and addresses on large placards to be hung us in hotel rotundas and other public places, page advertisements in city directories of private infirmaries for the treatment of diseases of a certain class, physicians' names on a piece of glass to fit on the telephone box, and the sending of notices of a physician's removal of his office to families on whom he has never practiced. As before stated, I have contended that these instances are palpable and gross violations of the spirit of the Code of Ethics. Please give your reply through the Journal.

M. D.

ANSWER :- Your own ideas relative to such conduct, as quoted in your query, are correct. Such things are frequently done in thoughtlessness, but more commonly are the result of a desire to obtain notoriety. Upon nothing is the Code so explicit as this. "It is derogatory to the dignity of the profession to resort to handbills, private cards or public advertisements, inviting the attention of individuals affected with particular diseases, publicly offering advice, etc." The methods mentioned are certainly equivalent to public handbills, etc. Skilled and reputable physicians do not need these methods to obtain practice, and others are better without it when they are compelled to resort to such schemes; or rather the profession would be better without them. (See Code, page 9, section 4.) Recently such an advertisement was observed by a prominent layman, who estimated the author of it justly as "One not possessing the requisite skill to obtain the confidence of the community." The sending of one's card, or notice of removal, to families on whom they have never practiced is very improper, a true bidding for practice.

\section{PUBLIC HEALTH.}

Smallpox in Germany Chiefly Imported.-Smallpox in Germany destroyed 65,000 lives per year a century ago. Now the average number is 114 per annum, and most of these are immigrants from those countries "over the border," where less stringent laws regarding compulsory vaccination exist.

Experimental Tests of Preventive Inoculation of Cholera.--Some interesting experiments have been made in Berlin recently with the results that inoculation of seventeen healthy men, most of them physicians whose names are well known to science, a guarantee of the accuracy of the observations, confirmed in every respect the results obtained by Dr. Haffkine in India. The experiments were carefully studied with control tests, and are described in the Deutsche med. Woch. of January 1. They show that the effect of inoculation lasts a year, and therefore if a cholera epidemic should gain foothold in any country, it could be stamped out by this means. It also refutes the objections raised by some physicians in India to Dr. Haffkine's work, which was described in this Journal, Dec. 5, 1896.
Length of Period of Contagion. - According to the circular recently sent to the principals of all the educational establish. ments in France, the period of isolation after smallpox, scarlet fever and diphtheria must be forty days after the first day of invasion, sixteen days after chickenpox, measles and mumps, while after whooping cough attendance at school should not be allowed until thirty days after the coughing spells have entirely disappeared. Tuberculosis is added to the list of contagious diseases, and the principals are instructed to inform the parents if a pupil's bronchitis, enteritis, etc., persists after a certain length of time, as hygienic measures are required in these cases, life in the open air, etc., impossible to secure in educational establishments; where the crowded rooms, etc., are distinctly injurious to the patient, while exposing others to contagion.

New Rules in Pentusylvania Regarding the Contagious Dead.-At a recent meeting of the State Board of Health of that State, Dr. Lee secured the adoption of the following new regulation When a body, dead of a contagious disease, is to be disinterred, the following precautions shall be strictly observed: " 1 . No one shall be present at the disinterment except those necessary to perform the labor and one adult male relative of the deceased. 2. A hermetically sealed zinc-lined box, sufficiently large to contain the box, coffin or casket already in the grave, shall be in readiness to receive the latter. 3. When within six inches of the top of receptacle containing the body, the earth shall be saturated witn one-fifth per cent. solution $(1-500)$ of bichlorid of mercury. 4. The receptacle containing the remains shall on no account be opened, but shall be at once placed in the box provided as above and hermetically sealed, and said box shall not be opened on arriving at the place of destination." This was adopted.

Good Results from Antidiphtherial Serum in Vienna.-Professor Paltauf of Vienna reports upon a year's experience with the heilserum. In 1,100 cases of diphtheria in various parts of Austria treated by antitoxin, 970 recoveries took place, a mortality of 12.5 per cent. The report furnishes strong evidence as to the great value of the treatment in the diminished mortal. ity, and also when it shows that the earlier the treatment is used the more effective is its action. In the cases where the injections were used as early as the second day of the disease, the mortality was 6.7 per cent., while in cases first treated on the third day it amounted to 19 per cent., and those treated on the fourth day to 24 per cent. On and after the sixth day it was upward of 33 per cent. When it is remembered that in previous years the mortality seldom was under 40 per cent. it is clear that we have in the antitoxin a measure exceeding all others in usefulness.

Anti-expectoration Regulations at Brooklyn and Boston.-In the spring of last year the presidents of all the surface and elevated railways of Brooklyn were notified by the Ccmmissioner of Health to conspicuously post in all passenger cars a notice reading as follows: "Spitting on the floors of public conveyances is a public nuisance and a source of danger to the public health. It is hereby prohibited. So ordered by the Commis sioner of Health." The employes of each company were required to enforce that order. As certain of the roads had not fully carried out that regulation, on Jan. 25,1897 , a peremptory notification to their officials was issued. The following notice has, by order of the Boston Board of Health, been posted in all the cars of the West End Street Railway Company, Boston: "The Board of Health adjudges that the deposit of sputum in the streetcars is a public nuisance, source of filth and cause of sickness, and hereby orders that spitting on the floors of streetcars be, and hereby is, forbidden." Above this order is posted a copy of the statute stating that the fine for infringement of an order of the Board of Health is $\$ 100$. The Chicago Health Department has issued a similar notice. 